\title{
Performance Analysis of An Automated Biodiesel Processor
}

\author{
Adib Bin RASHID ${ }^{1 *}$, Md. Faisal KADER ${ }^{2}$ \\ ${ }^{1}$ Industrial and Production Engineering Department, Military Institute of Science and Technology (MIST), \\ Dhaka, Bangladesh \\ ${ }^{2}$ Mechanical Engineering Department, Bangladesh Military Academy (BMA), Bhatiary, Chattogram, \\ Bangladesh
}

\begin{abstract}
The extraction of Biodiesel from vegetable oil is time-consuming and requires human involvement to perform and keep track of chemical titration, stirring, and washing the product for each batch of production. A well-designed system can significantly eliminate human interaction and expedite the whole process. The construction of an inexpensive automated biodiesel plant can help produce Biodiesel on a large scale and make a breakthrough in Bangladesh's economy as no such effort has been undertaken so far. To achieve the desired aim, this paper focuses on implementing the construction of a cheap, compact, and automatic system that will exhaustively reduce human interactions and the processing time and increase biodiesel yield. For this purpose, an automated biodiesel processor was designed and constructed in conjunction with pumps, solenoid valves, level sensors, temperature sensors, etc., using a programmable logic controller (PLC). Upon completing a full cycle, the plant delivers certified Biodiesel and the leftover by-products are collected for further recycling. Different batches of Biodiesel were produced. A comparative study of the physical properties of the fuel and the diesel engine's performance characteristics by these fuel samples was analysed and showed satisfactory results.
\end{abstract}

Keywords - Alternative energy; biodiesel; biodiesel processor; programmable logic controllers; vegetable oil

\section{INTRODUCTION}

The inevitable depletion of fossil fuel-based energy sources combined with global warming and radical climate change motions a grim fate for all of us, which has compelled researchers to look into more viable and environmentally friendly energy sources [1], [2]. Consequently, biodiesel production has come under the limelight with a hope to replace the dwindling fossil fuels. Though an entire replacement might not be possible, a suitable blend of Biodiesel and petroleum diesel can significantly reduce environmental contamination. A significant challenge is to invent a way to make the production process cheaper and faster. The Transesterification process is the conventional process in which vegetable oil is reacted with monohydric alcohol in the presence of a catalyst [3]-[6]. The following reaction expresses transesterification.

\footnotetext{
* Corresponding author.

E-mail address: adib8809@gmail.com
} 


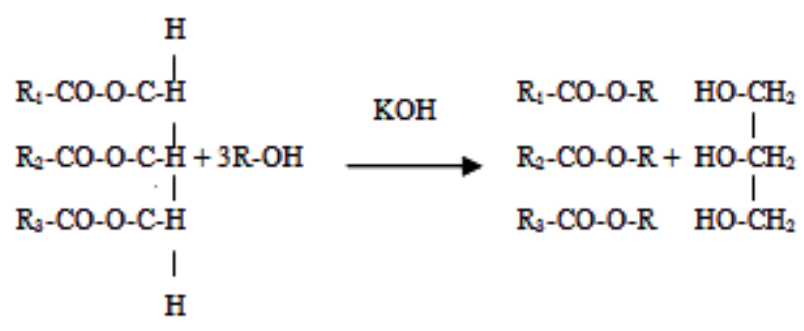

Oil of fats Alcohol Biodiesel Glycerine

Fig. 1. A schematic depiction of the transesterification of triglycerides (vegetable oil) with methanol to generate fatty acid methyl esters (Biodiesel).

The entire process requires a human operator to run and monitor the Transesterification system and interfere whenever needed. To make the process faster an advanced and smart system is required. Hence, many researchers have developed an automated plant to produce Biodiesel at minimum effort [7]-[14]. Daniyan et al. [10] set a smart multi-feedstock biodiesel plant to engender Biodiesel. Highina et al. [11] produced Biodiesel from Jatropha oil where $93 \%$ of triglycerides have been converted to methyl esters due to using a batch reactor. Leevijit et al. [12] modelled an ideal continuous stirred tank reactor and performed a simulation to optimize a mixing performance for producing Biodiesel from palm oil and to predict required production times at the desired purities for transesterification of palm oil.

On the other hand, Ghazi et al. [13], with the help of ASPEN PLUS simulation software, discussed an Oscillatory Flow Biodiesel Reactor (OFBR) for producing Biodiesel from Jatropha oil. Ghobadian et al. [14] designed, fabricated, and evaluated a novel biodiesel processor system with a 70-litre capacity of batch-type stirred tank reactor (STR). For efficient mixing, both mechanical and hydraulic mixing has been incorporated. Also, the vacuum distillation method for methanol recovery, an electrostatic coalescing method for glycerin separation, and ion exchange dry wash are provided to increase the production capability and purity of Biodiesel.

Waste cooking oil could be converted into Biodiesel and several researchers have successfully developed many technologies to convert waste cooking oil into biodiesel [15] [21]. In the presence of potassium hydroxide (catalyst) with $1 \%$ by weight of waste vegetable oil, Amir et al. [22] manufacture biodiesel using a stirred batch reactor where waste vegetable oil and methanol are combined at a molar ratio of 1:6. Samad et al. [23] also designed a portable biodiesel plant that can produce Biodiesel up to $99.8 \%$ with a relatively shorter time from waste cooking oil.

This project attempts to build an automated system that will reduce operator interaction and make the system affordable and completely portable. The system also has some options to change a few operating parameters such as time, rpm, and temperature so that the final product can be studied for further optimization. Therefore, the project's primary aim is to explore better and faster alternatives to biodiesel production and its commercialization.

\section{Process Design}

This project aimed at constructing an inexpensive and automated biodiesel plant that would help mass production of Biodiesel without manual observation. This is the first attempt ever undertaken in Bangladesh to produce Biodiesel in an automated production system. The plant is about five feet high, completely portable, and can fit into any corner. It is powered by a $220 \mathrm{~V}$ AC supply and can be used in both homes and industries to produce Biodiesel. The 
plant has different compartments for different raw material inputs. After all the inputs are given, it only requires turning on the machine. The standard time and temperature for the reaction are pre-set; however, they can be changed as per the requirements. Currently, the plant in its miniature form can produce 10 litres of Biodiesel in 24 hours, including the waiting time after trans-esterification reaction and water wash time for 4 hours. The complete final product can be extracted after 20 hours and the by-product glycerine is also extracted out separately. It can be used again to recover methanol for further biodiesel production. The plant has simple construction geometry and can be built locally and it's very much on the budget. In Bangladesh biodiesel was conventionally produced in the laboratory for research purposes, but this plant can be used to produce Biodiesel for both research and commercial purpose conveniently.

A process flow diagram of biodiesel production by the automated biodiesel plant is shown in Fig. 2. In a $10 \mathrm{~L}$ chemical tank, sodium methoxide is produced by an exothermic reaction between methanol and lye. From this point on, operators should keep a strategic distance from standing over the tanks, as any discharged vapours can be destructive or lethal.

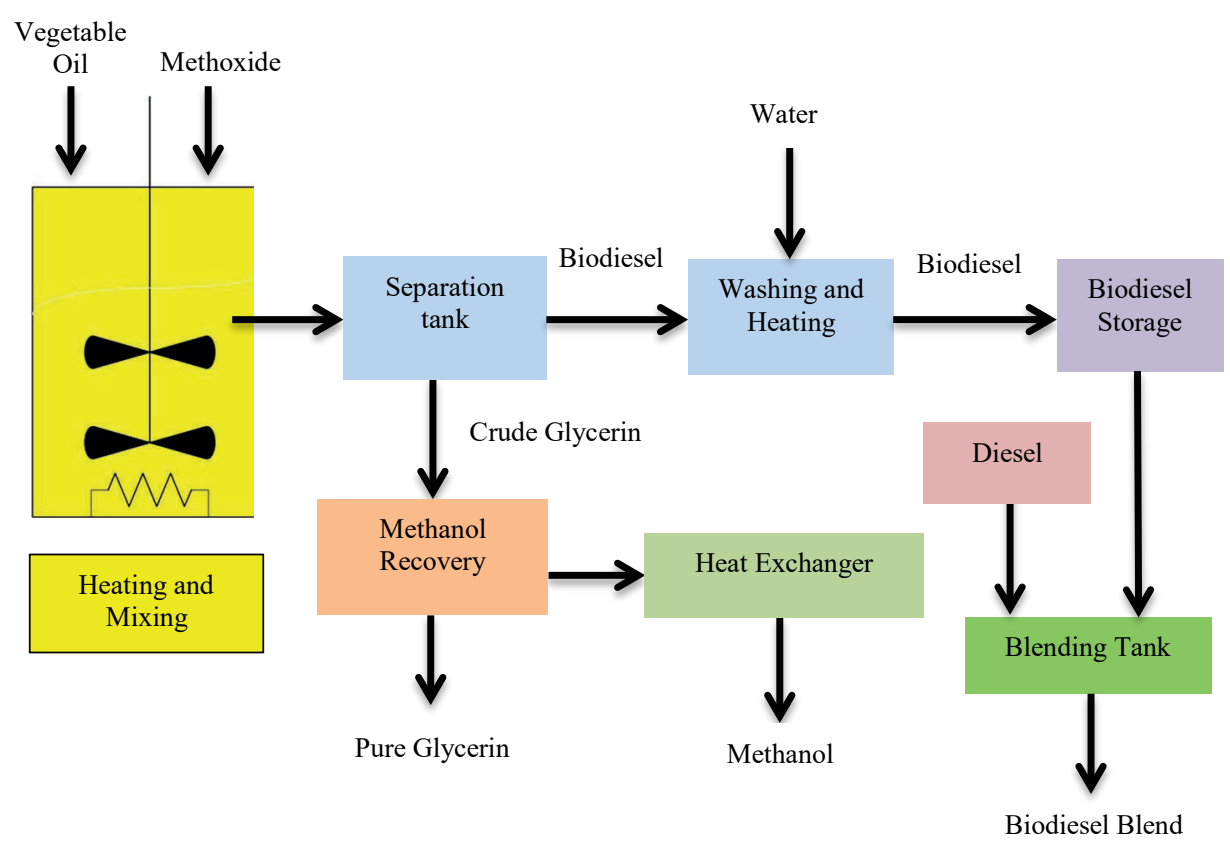

Fig. 2. Process flow diagram of overall Biodiesel Production Process.

In the first step, the vegetable oil is reheated between $50-65{ }^{\circ} \mathrm{C}$. Then sodium methoxide is added and mixed for at least one hour using a stirrer. A while later, the blend is permitted to cool to room temperature and after that pumped to the settling/wash tank and permitted to settle for roughly 12 hours. The glycerine was separated and settled into the wash tank bottom and depleted to the methanol recovery unit.

The final step in the preparation of biodiesel is to eradicate any soap, water, methanol, and other contaminants through a few wet washing cycles with water, and each cycle takes 4 hours of settling/separation period. Then the filthy water must be appropriately disposed of. 


\section{Design And Construction of Biodiesel Processor}

Fig. 3 shows the portable biodiesel processing plant which is divided into three separate sections. The two stainless steel tank is situated to store vegetable oil and methoxide on top of the plant. The plant's middle section consists of the reactor, separator, washing tank, Control electronics, and a blending tank. The plant's bottom part contains a Diesel storage tank, Biodiesel storage tank, pressure pumps, and methanol recovery unit.

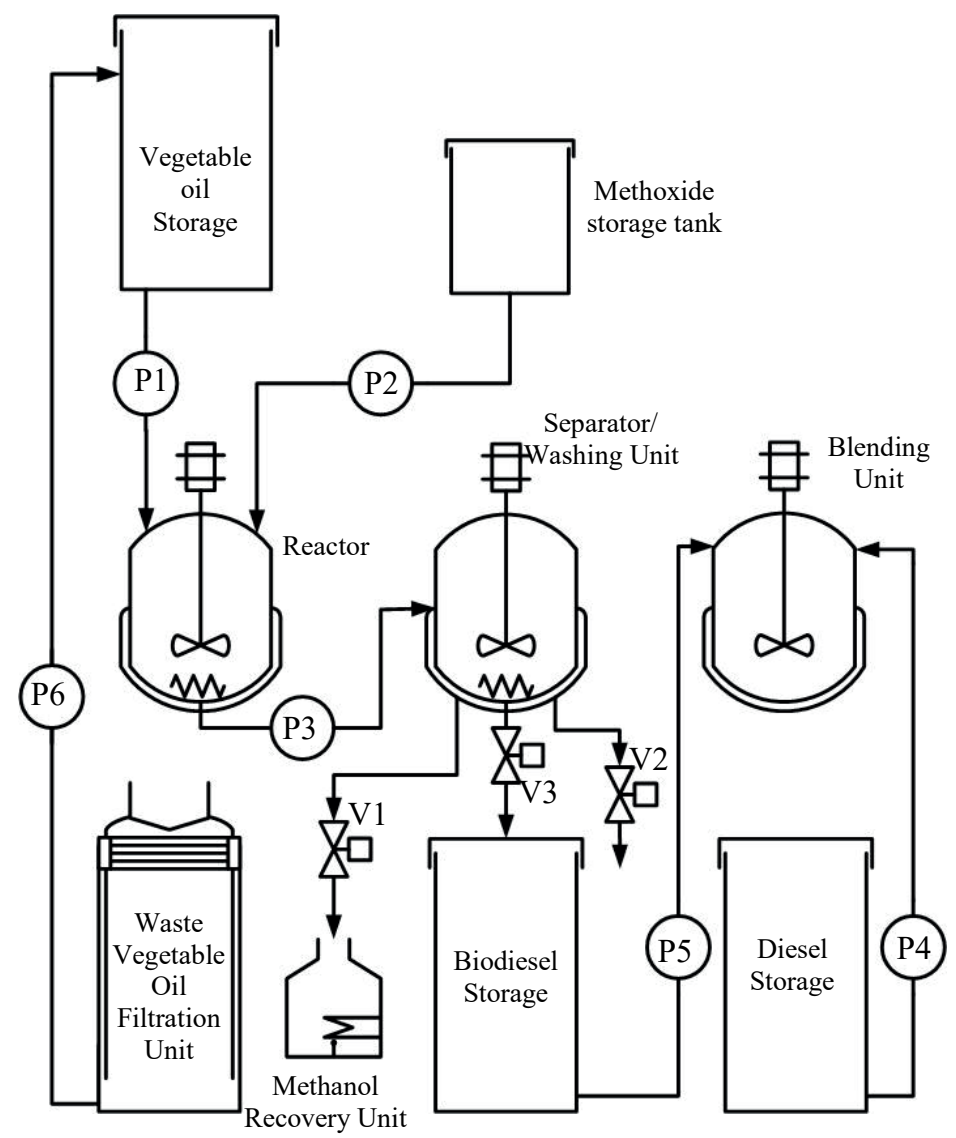

Fig. 3. Schematic diagram of the portable-biodiesel-processing-unit.

\subsection{Filtration of Waste Oil}

As shown in Fig. 4, for separating impurities and suspended particles, at first, the waste cooking oil is passed through a fine strainer network manually. As the liquid passes through the strainer, the particles are collected because they are not small enough to pass through the screen gaps. For removing water, oil is heated to $60{ }^{\circ} \mathrm{C}$ for 15 minutes and kept for 24 hours to settle down. Compared to direct evaporation, the benefit of this technique is the reduction of free fatty acid production.

The system is also designed with an automated filtration system to remove impurities from the WVO. The strained and heated oil is pumped through 15 -micron and 10-micron filters to 
block water, dirt, and impurities. This process may be run twice to produce better overall Biodiesel.

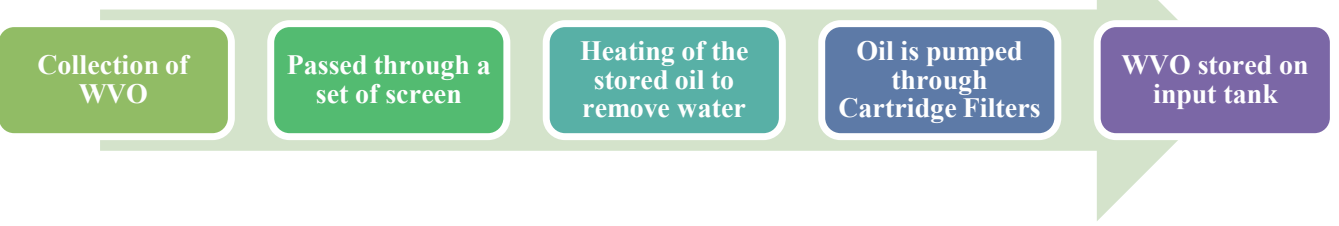

Fig. 4. Process flow diagram of the filtration of waste cooking oil.

\subsection{Reactor}

In biodiesel production, the reactor is the main part of the process where the chemical reaction takes place. The tank designed for the reactor has a capacity of 10 litres and the tank is built from a $3 \mathrm{~mm}$ sheet of stainless steel. Each container's heating system is outfitted with a $1000 \mathrm{~W}$ heating coil, a temperature sensor, and a digital thermometer to monitor and adjust the temperature. The sensor's electrical signals enable the heater to be turned on or off. An electrical motor is used to stir up the mixing. The transport of raw materials (reactants) and products between the tanks were carried out using two pumps of $0.5 \mathrm{HP}(0.37 \mathrm{~kW})$.

\subsection{Separation, Washing and Drying Unit}

After the proper mixing, the mixture is transferred to the Separator/Wash tank by a $0.5 \mathrm{HP}$ pressure pump. The Tank is similar to the reactor tank having a capacity of 10 litres fabricated with a $3 \mathrm{~mm}$ sheet of stainless steel. It has a stirrer attachment on the top of the vessel and three different solenoid valves at the bottom for disposing of pure Biodiesel, glycerine, and wastewater. There is a 1000-watt heater element to heat the Biodiesel to remove water from it.

The mixture is then given a specific time to respond and settle into separating Biodiesel and glycerine layers. The glycerine generated settles at the bottom of the mixing tank and is evacuated by a hosepipe from the tank that leads to the glycerine storage tank by opening the solenoid valve (valve 1) at the bottom of the Separating tank

When the glycerine is taken out, the water inlet valve (valve 2) is opened. The Biodiesel is washed to eliminate any soap, water, methanol, and other impurities from Biodiesel that were inadvertently produced amid the preparation. After the washing, the Biodiesel is heated to $110^{\circ} \mathrm{C}$ to remove any leftover water from the Biodiesel.

\subsection{Methanol Recovery Unit}

In the biodiesel phase, methanol is the costliest input. Methanol costs are related to oil prices and, as such, are at risk of volatility as crude prices increase.

The glycerine by-product is poured into a sturdy and air-tight stainless-steel container through a flexible pipe connected to the lid cover. An electric heater heats the glycerine above methanol's boiling point $\left(65^{\circ} \mathrm{C}\right)$. The vapours rise through the bucket and into a length of copper tubing which is then entered into a condenser. As the cold tap water passes through the condenser, methanol vapours turn into liquid which falls through the copper tubing and is collected in a closed glass bottle. The rest over glycerine is also drained from a tap. 


\subsection{Blending Unit}

Biodiesel can be mixed and used in various distinctive quantities with petroleum diesel. They include B100 (pure biodiesel), B20 (mixture of $20 \%$ biodiesel, and $80 \%$ petroleum diesel), B10 (mixture of $10 \%$ biodiesel, and $90 \%$ petroleum diesel) B5 (mixture of $5 \%$ biodiesel, and $95 \%$ petroleum diesel), and B2 (mixture of $2 \%$ biodiesel, and $98 \%$ petroleum diesel) [24].

In diesel engines with no or just slight modifications, blends of 20 percent biodiesel and less can be used. However, the pure form of Biodiesel (B100) can also be used with minor engine modifications [25].

B20, which meets the performance characteristics needed by the Energy Policy Act (EPAct) of 1992, is the most popular biodiesel blend [26].

The two separate $0.5 \mathrm{HP}$ pump diesel and Biodiesel are transported on the blending tank situated on the middle section of the plant. The tank is also a $3 \mathrm{~mm}$ thick stainless-steel tank having a capacity of $10 \mathrm{~L}$. Over the tank, a stirrer is attached to mix the diesel and Biodiesel uniformly.

\subsection{Programmable Logic Controller (PLC) Programming}

The final step included composing a PLC program to control the whole procedure. Siemens S7-200 CPU 222 PLC controller is used in the biodiesel processor because of its versatility use in the industry. It has numerous inputs and yield capabilities and is simple to program. Other than that, the PLC will permit the administrator to include numerous things in the method, such as flow meters, temperature devices, timers, solenoid valves, and pumps very effortlessly. For each operation to occur, the processor operates on an input/output basis.

The controller sends an output signal (start mixing, turn the heater on, etc.) when the input signal/signals are received (a given temperature, elapsed time, etc.).

On the PLC panel, there are three buttons: a green start button, a red stop button, and a clear green reset button. The red stop button can be pressed to pause the processor at any time. To stop the program, the reset button may also be used and it must be pressed to reset the counters in the program after the stop button is pressed. The ladder programming language is used to program the PLC for the smooth operation of the Biodiesel Processor.

\section{RESUlt AND DisCUSSION}

\subsection{Performance Analysis of the Automated Plant}

To perform the test, Biodiesel is generated by the $6: 1$ molar ratio of oil to alcohol and in the presence of $\mathrm{KOH}$ catalyst with an amount of $1 \%$ of the oil weight. The experiments were carried out based on three variable factor stages, the velocity of the stirrer $(450,500,550$, 600 , and $650 \mathrm{rpm})$ and the reaction time $(20,30,40,50$, and $60 \mathrm{~min})$ at a constant temperature of $50{ }^{\circ} \mathrm{C}$. Performance analysis results of the Automated Biodiesel Plant are presented in Fig. 5 and Fig. 6. 

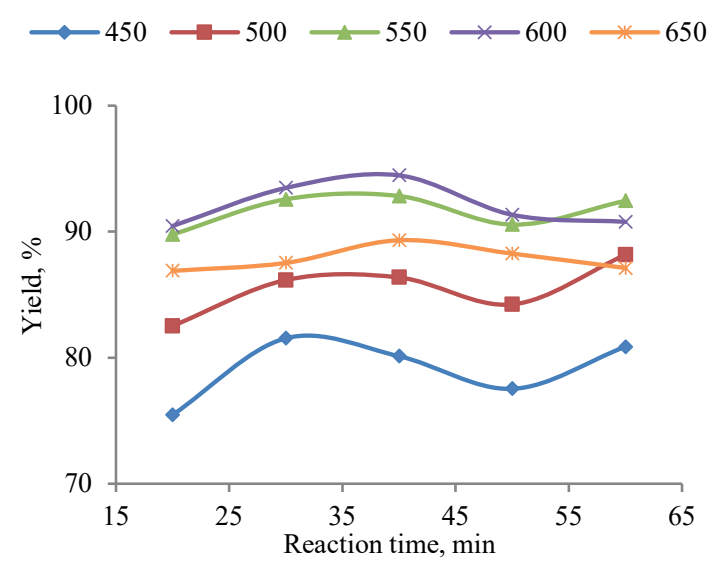

Fig. 5. Effect of mixing time on the biodiesel conversion rate from Waste Soybean Oil.

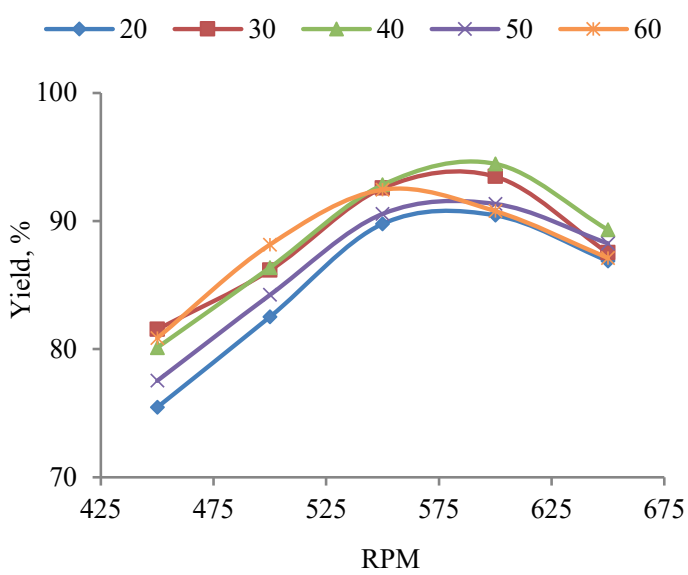

Fig. 6. Effect of stirring velocity on biodiesel production from Waste Soybean Oil.

\subsubsection{Effect of Mixing Time on the Yield of Biodiesel Production at the Reactor}

Fig. 5 shows that $90 \%$ ester conversion occurred within the first 30 minutes. The solution is stirred for 20, 30, 40, 50 and 60 minutes and from the graph, it is clear that after 30 minutes, the conversion rate is insignificant. In the presence of potassium hydroxide $(\mathrm{KOH})$, the transesterification process starts by combining methanol and vegetable oil. Due to the low solubility of alcohol in oil, the volume of reaction is initially small and rises in the second stage [27]-[29]. Finally, the utilization of reactants diminishes and comes to harmony.

\subsubsection{Effect of Stirring Velocity on the Yield Biodiesel Production at the Reactor}

Fig. 6 depicts that with the increment of stirring velocity, the biodiesel generation rate increases and touches its supreme at around $600 \mathrm{rpm}$. There are collisions between molecules insoluble in alcohol and oils with increasing stirrer speed and form a homogeneous point, 
expanded and more mass transfer occurs. Higher stirring velocity causes a higher transformation rate at a lower time [30], [31]. In any case, an extreme blending rate may lessen the response rate.

\subsection{Characterization of Biodiesel Blends}

Biodiesel (methyl esters) properties made from waste cooking soybean oil are quite comparable to that of diesel fuel. Transesterification reaction improves the anticipated fuel properties of oil like density, kinematic viscosity, flash point, fire point, cloud point, pour point, and calorific value [32]-[35].

Using a Saybolt viscometer, the viscosity was measured. Flashpoint and fire points were measured by closed cup instruments, while a bomb calorimeter was used to calculate the calorific value. The comparison of fuel properties of waste cooking oil, biodiesel blends, and diesel is shown in Table 1.

Table 1. Properties of Waste CoOking Oil, Biodiesel, Diesel and Their Blends

\begin{tabular}{lllll}
\hline Fuel Type & $\begin{array}{l}\text { Density, } \\
\text { gm/. } \mathbf{c m}^{\mathbf{3}}\end{array}$ & $\begin{array}{l}\text { Kinematic Viscosity, } \\
\mathbf{m m}^{2} / \mathbf{s e c}\end{array}$ & Flashpoint & $\begin{array}{l}\text { Calorific value, } \\
\mathbf{M J} / \mathbf{k g}\end{array}$ \\
\hline Waste cooking Oil & 0.93 & 32.5 & 286 & 37.3 \\
Diesel & 0.84 & 4.05 & 65 & 45.8 \\
Biodiesel (B100) & 0.92 & 5.60 & 172 & 37.9 \\
Biodiesel (B20) & 0.87 & 4.90 & 78 & 42.8 \\
Biodiesel (B40) & 0.89 & 5.20 & 82 & 41.3 \\
\hline
\end{tabular}

The comparisons indicate that biodiesel is comparatively closer to diesel fuel in fuel characteristics. From a value of 32.5 to $5.6 \mathrm{~mm}^{2} / \mathrm{sec}$, the viscosity was significantly reduced.

The flash and fire point was greater than that of conventional diesel for waste cooking biodiesel. The flashpoint of the resulting blend can be increased by a small percentage of the addition of biodiesel to diesel; this blend is also safe to store and transport [36].

\subsection{Engine Performance Analysis}

The experimental setup consisted of an engine bed, water brake dynamometer, load indicator, supply tank, fuel input measuring system, air intake measuring system, digital panel board, etc. To measure the temperature of the exhaust gas and lubricating oil, K-type thermocouples are used.

TABLE 2. ENGINE SPECIFICATION

\begin{tabular}{ll}
\hline Item & Specification \\
\hline Absolute Maximum Power & $3.5 \mathrm{~kW}(4.8 \mathrm{hp})$ at $3600 \mathrm{rev} / \mathrm{min}$ \\
Continuous Rated Power & $3.1 \mathrm{~kW}$ at $3000 \mathrm{rev} / \mathrm{min}$ \\
Bore & $69 \mathrm{~mm}$ \\
Stroke/Crank Radius & $62 \mathrm{~mm} / 31 \mathrm{~mm}$ \\
Connecting Rod Length & $104 \mathrm{~mm}$ \\
Engine Capacity & $232 \mathrm{~cm}^{3}(0.232 \mathrm{~L})$ or $232 \mathrm{cc}$ \\
Compression Ratio & $22: 1$ \\
Oil Type & Multigrade SAE $5 \mathrm{~W}-40$ \\
Oil Capacity & $2.6 \mathrm{~L}$ \\
\hline
\end{tabular}


Table 2 includes the specification of the engine used for experimentation. The set-up allows motor brake power, fuel consumption, air consumption, heat balance, thermal efficiency, volumetric efficiency, etc. to be studied.

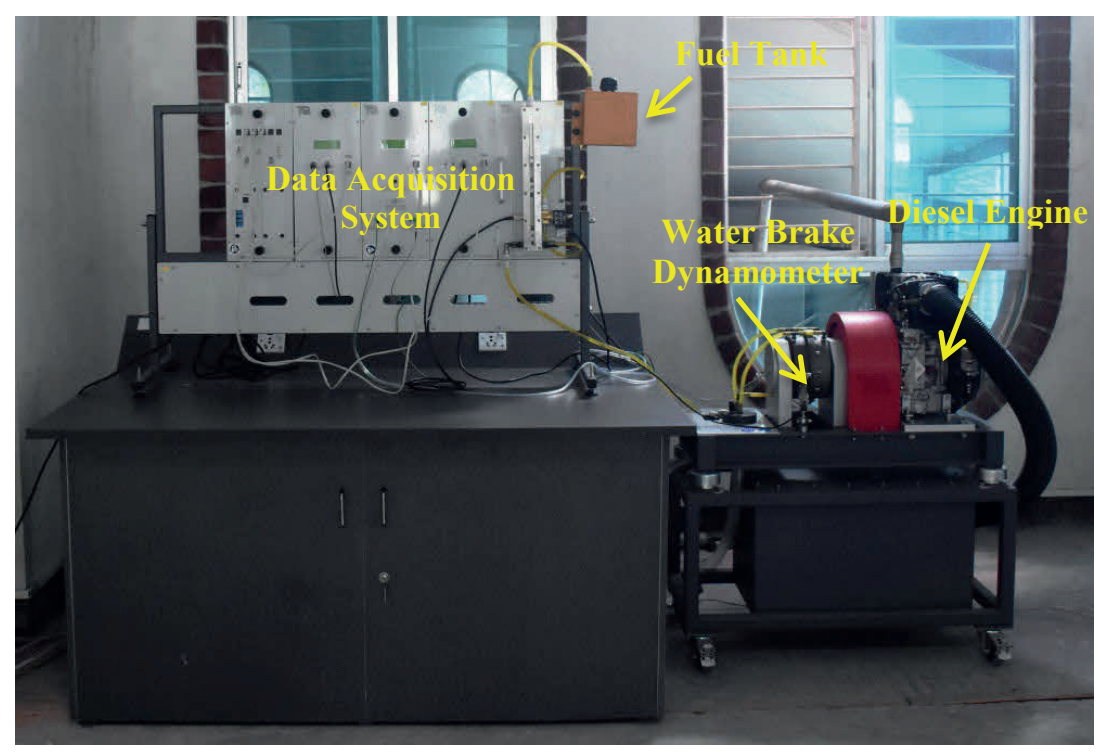

Fig. 7. The single-cylinder CI engine with water brake dynamometer and data acquisition system.

\section{Comparison of Engine Performance Characteristics}

Variation of Brake Specific Fuel Consumption (BSFC) and thermal efficiency with power produced (BHP - Brake Horse Power) is shown in Fig. 8 and Fig. 9, respectively. BSFC was found to be the highest when the engine is running with low power. This decreases when engine power approached the engine's rated power and then slightly increases at the end.

Since the density and heating values of diesel and the two blends are different, the real comparative picture is exhibited in the variation of thermal efficiency. Diesel thermal efficiency was found to be highest for diesel and slightly lower for B20 and B40.

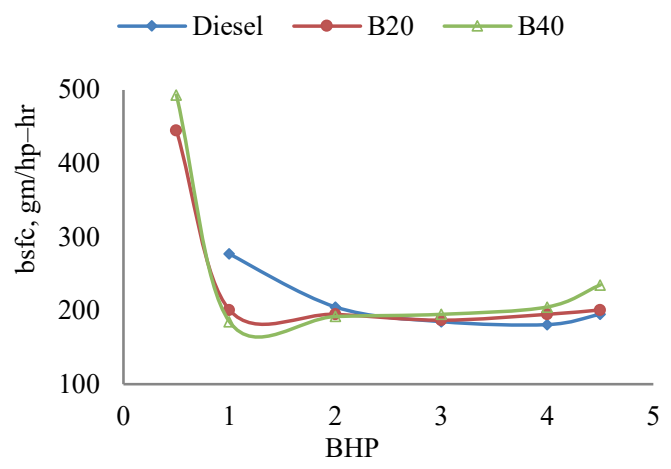

Fig. 8. Performance characteristics between BHP vs. Bsfc for Diesel and Biodiesel Blends. 


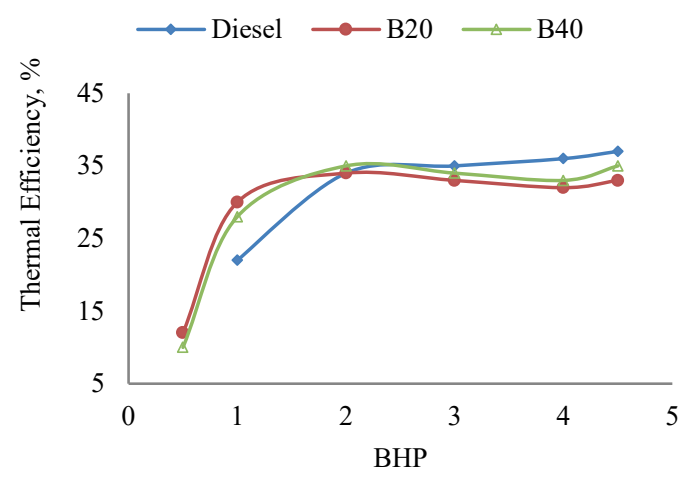

Fig. 9. Performance Characteristics between BHP vs. Thermal Efficiency for Diesel and Biodiesel Blends.

\subsection{Comparison of Emission Characteristics}

MAHA-MGT 5 with integrated MDO 2 LON Diesel Engine Emission Tester is used in this experiment. This Meter can efficiently measure and analyse exhaust gas temperature, HC, $\mathrm{CO}, \mathrm{CO}_{2}, \mathrm{O}_{2}$, and $\mathrm{NO}_{\mathrm{X}}$. From Figs. 10-12, it is reported that exhaust emissions of $\mathrm{B} 20$ and $\mathrm{B} 40$ had a significant reduction in $\mathrm{HC}, \mathrm{CO}$, and $\mathrm{CO}_{2}$ emissions compared to that of Diesel Fuel. This is due to enhanced fuel combustion, which is enabled by the additional oxygen content of biodiesel [37]-[39].
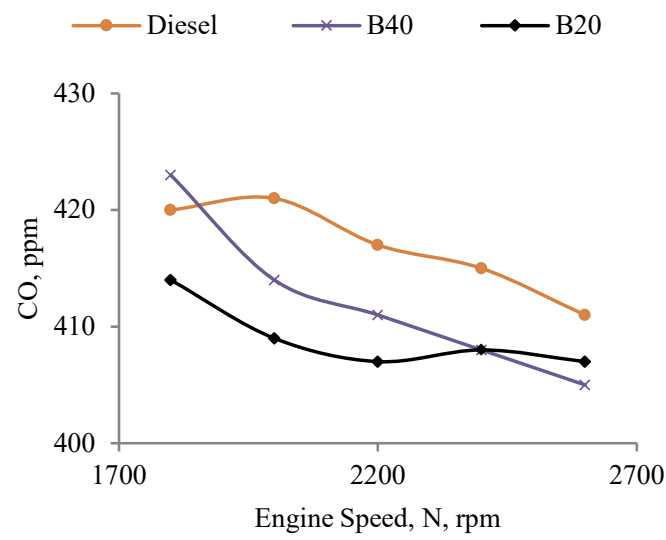

Fig. 10. $\mathrm{CO}$ emission in diesel engine for diesel and biodiesel blends. 


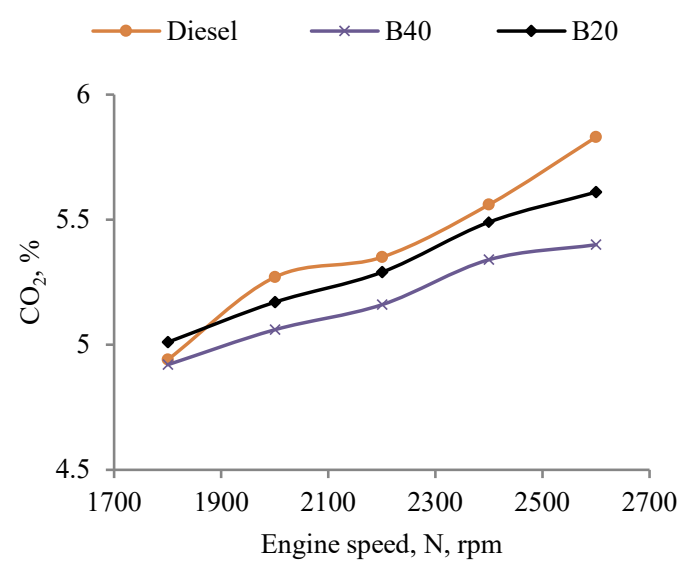

Fig. 11. $\mathrm{CO}_{2}$ emission in diesel engine for diesel and biodiesel blends.
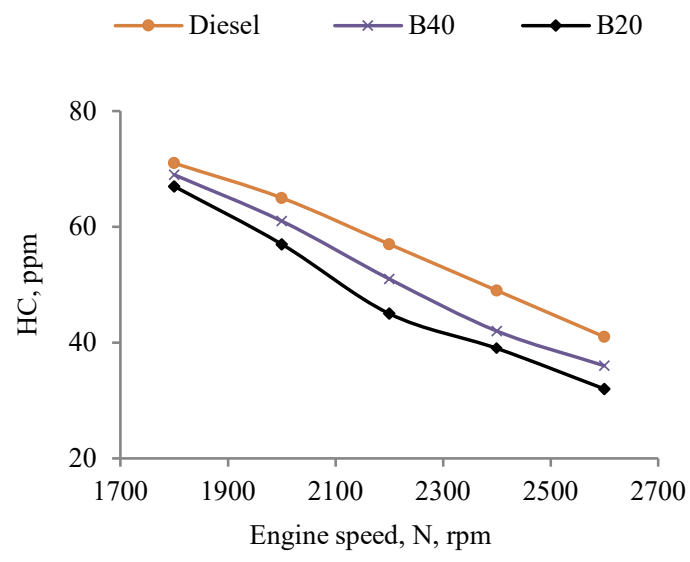

Fig. 12. HC emission in diesel engine for diesel and biodiesel blends.

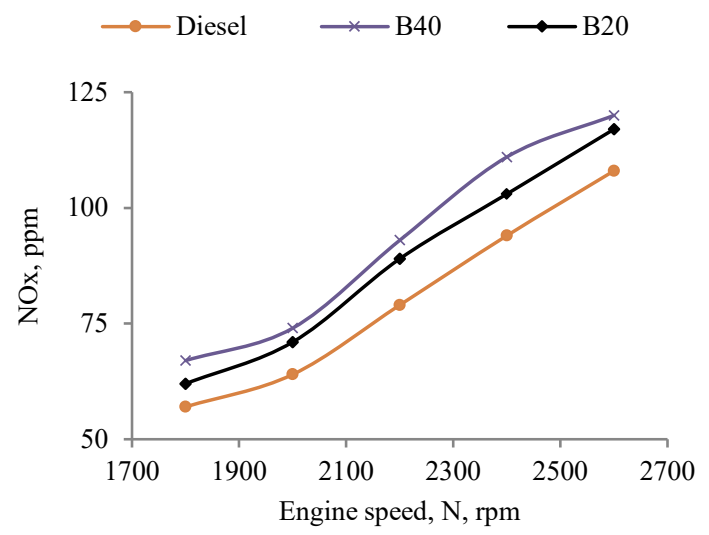

Fig. 13. $\mathrm{NO}_{\mathrm{x}}$ emission in diesel engine for diesel and biodiesel blends. 
Fig. 13 displays the disparity of $\mathrm{NO}_{\mathrm{X}}$ emission with numerous engine speeds for biodiesel blends and neat diesel. The figure shows that $\mathrm{NO}_{\mathrm{X}}$ emission with $\mathrm{B} 20$ and $\mathrm{B} 40$ is higher than that of neat diesel. Biodiesel contains extra oxygen, ensuring better combustion of fuel and high cylinder temperature [40]-[43]. Hence, at high combustion temperature, this oxygen reacts with nitrogen and causes excessive $\mathrm{NO}_{\mathrm{X}}$ emission.

\section{CONCLUSiOn}

The ultimate objective of this project is to develop and manufacture an automated biodiesel processor to minimize the processing time and, with very limited operator involvement, increase biodiesel yield. It is evident that $90 \%$ ester conversion occurred within the first 30 minutes. Again, with the increment of stirring velocity, the biodiesel generation rate increases and touches its supreme at around $600 \mathrm{rpm}$.

The Biodiesel produced was investigated for fuel property analysis and meets ASTM standards and is utilized effectively in running a diesel engine. The comparisons indicate that biodiesel produced from the automated plant is comparatively closer to standard diesel fuel. From the Engine performance analysis, Diesel's thermal efficiency was found to be highest for diesel and slightly lower for Biodiesel Blends (B20 and B40). It is also reported that exhaust emissions of $\mathrm{B} 20$ and $\mathrm{B} 40$ had a significant reduction in $\mathrm{HC}, \mathrm{CO}$, and $\mathrm{CO}_{2}$ emissions compared to that of Diesel Fuel.

\section{ACKNOWLEDGEMENT}

The authors are thankful for the opportunities to use the laboratories of the Mechanical Engineering Department of Bangladesh Military Academy.

\section{REFERENCES}

[1] Sajjadi B., Raman A. A. A., Arandiyan H. A comprehensive review on properties of edible and non-edible vegetable oil-based biodiesel: Composition, specifications, and prediction models. Renewable and Sustainable Energy Reviews 2016:63:62-92. https://doi.org/10.1016/j.rser.2016.05.035

[2] Ogunkunle O., Ahmed N. A. A review of global current scenario of biodiesel adoption and combustion in vehicular diesel engines. Energy Reports 2019:5:1560-1579. https://doi.org/10.1016/j.egyr.2019.10.028

[3] Ganesan D., Rajendran A., Thangavelu V. An overview on the recent advances in the transesterification of vegetable oils for biodiesel production using chemical and biocatalysts. Reviews in Environmental Science and Bio/Technology 2009:8:367. https://doi.org/10.1007/s11157-009-9176-9

[4] Schuchardt U., Sercheli R., Vargas R. M. Transesterification of vegetable oils: a review. Journal of the Brazilian Chemical Society 1998:9(1):199-210.

[5] Sukasem N., Manophan S. The development of biodiesel production from vegetable oils by using different proportions of lime catalyst and sodium hydroxide. Energy Procedia 2017:138:991-997. https://doi.org/10.1016/j.egypro.2017.10.108

[6] Yadav C., et al. Thermo-analytical characterizations of biodiesel produced from edible and non-edible oils. Fuel Processing Technology 2017:167:395-403. https://doi.org/10.1016/j.fuproc.2017.07.026

[7] Tiwari A., Rajesh V. M., Yadav S. Biodiesel production in micro-reactors: A review. Energy for Sustainable Development 2018:43:143-161. https://doi.org/10.1016/j.esd.2018.01.002

[8] Diaz M. S., Espinosa S., Brignole E. A. Model-Based Cost Minimization in Non-Catalytic Biodiesel Production Plants. Energy and Fuels 2009:23:5588-5593. https://doi.org/10.1021/ef900338k

[9] Narasimhan V., et al. Process Incentives by the Intensification of a Conventional Biodiesel Plant. Procedia Technology 2016:24:661-668. https://doi.org/10.1016/j.protcy.2016.05.177

[10] Daniyan O., et al. Performance Evaluation of a Smart Multi feedstock Biodiesel Plant. Procedia Manufacturing 2019:35:1117-1122. https://doi.org/10.1016/j.promfg.2019.06.065 
[11] Highina B. K., Bugaje I. M., Umar B. Biodiesel production from Jatropha caucus oil in a batch reactor using zinc oxide as catalyst. Journal of Petroleum Technology and Alternative Fuels 2011:2(9):146-149.

[12] Leevijit T., et al. Design and test of a continuous reactor for palm oil transesterification. S J Sci Tech 2006:28(4):791802.

[13] Azhari I., et al. Preliminary design of oscillatory flow biodiesel. Reactor for continuous biodiesel production from jatropha triglycerides. Journal of Engineering Science and Technology 2008:3(2):138-145.

[14] Abbaszaadeh A., et al. Design, Fabrication, and Evaluation of a Novel Biodiesel Processor System. Int J Ren En Tech Res 2013:2(12):249-255.

[15] Zhang Y., et al. Biodiesel production from waste cooking oil: 1. Process design and technological assessment. Bioresource Technology 2003:89:1-16. https://doi.org/10.1016/S0960-8524(03)00040-3

[16] Thi Tuong V. T., et al. Green biodiesel production from waste cooking oil using an environmentally benign acid catalyst. Waste Management 2016:52:367-374. https://doi.org/10.1016/j.wasman.2016.03.053

[17] Ullah Z., et al. Preparation and kinetics study of biodiesel production from waste cooking oil using new functionalized ionic liquids as catalysts. Renewable Energy 2017:114:755-765. https://doi.org/10.1016/j.renene.2017.07.085

[18] Joshi S., et al. Intensification of biodiesel production from soybean oil and waste cooking oil in the presence of heterogeneous catalyst using high speed homogenizer. Ultrasonics Sonochemistry 2017:39:645-653. https://doi.org/10.1016/j.ultsonch.2017.05.029

[19] Tan Y. H., et al. Waste Ostrich and Chicken-Eggshells as Heterogeneous Base Catalyst for Biodiesel Production from Used Cooking Oil: Catalyst Characterization and Biodiesel Yield Performance. Applied Energy 2015:160:58-70. https://doi.org/10.1016/j.apenergy.2015.09.023

[20] Yusuff A. S., et al. Development and Characterization of a Composite Anthill- Chicken Eggshell Catalyst for Biodiesel Production from Waste Frying Oil. International Journal of Technology 2018:9(1):110-119. https://doi.org/10.14716/ijtech.v9i1.1166

[21] Al-Zuhair S., Dowaidar A., Kamal H. Dynamic Modelling of Biodiesel Production from Simulated Waste Cooking Oil Using Immobilized Lipase. Biochemical Engineering Journal 2010:44(2-3):256-262. https://doi.org/10.1016/j.bej.2009.01.003

[22] Nezhad A. H., Hashemi S. J., Tabatabaie S. R. Biodiesel production from waste cooking oil using a stirred batch reactor. J Nov App Sci 2014:3(10):1125-1130.

[23] Samad A. T., et al. Design of portable biodiesel plant from waste cooking oil. Energy Procedia 2018:153:263-268. https://doi.org/10.1016/i.egypro.2018.10.062

[24] Drive Clean Colorado. Alternative Fuels. Biodiesel [Online]. [Accessed 16.06.2020]. Available: https://drivecleancolorado.org/resources/alternative-fuels\#/find/nearest

[25] Alleman L. T., et al. Biodiesel Handling and Use Guide (Fifth Edition). United States: CC, 2016.

[26] American Society for Testing and Materials. ASTM International. [Online]. [Accessed: 16.06.2020]. Available: https://www.astm.org/d7467-20a.html

[27] Tiwari A., Rajesh V., Yadav S. Biodiesel production in micro-reactors: A review. Energy for Sustainable Development 2018:43:143-161. https://doi.org/10.1016/j.esd.2018.01.002

[28] Joshi S., et al. Intensification of biodiesel production from soybean oil and waste cooking oil in the presence of heterogeneous catalyst using high speed homogenizer. Ultrasonics Sonochemistry 2017:39:645-653. https://doi.org/10.1016/j.ultsonch.2017.05.029

[29] Naveen S., et al. Novel Solar Parabolic Trough Collector cum Reactor for the Production of Biodiesel from Waste Cooking Oil using Calcium Oxide catalyst derived from seashells waste. Chemical Engineering and Processing Process Intensification 2020:157:108145. https://doi.org/10.1016/j.cep.2020.108145

[30] García-Martín J. F., et al. Biodiesel production from waste cooking oil in an oscillatory flow reactor. Performance as a fuel on a TDI diesel engine. Renewable Energy 2018:125:546-556. https://doi.org/10.1016/i.renene.2018.03.002

[31] Panchal B., et al. Optimization of soybean oil transesterification using an ionic liquid and methanol for biodiesel synthesis. Energy Reports 2019:6(7):20-27. https://doi.org/10.1016/j.egyr.2019.11.028

[32] Bencheikh K., et al. Fuels properties, characterizations and engine and emission performance analyses of ternary waste cooking oil biodiesel-diesel-propanol blends. Sustainable Energy Technologies and Assessments 2019:35:321-334 https://doi.org/10.1016/j.seta.2019.08.007

[33] Madiwale S., Bhojwani V. An Overview on Production, Properties, Performance and Emission Analysis of Blends of Biodiesel. Procedia Technology 2016:25:963-973. https://doi.org/10.1016/j.protcy.2016.08.189

[34] Szabados G., Bereczky Á. Experimental investigation of physicochemical properties of diesel, Biodiesel and TBKbiodiesel fuels and combustion and emission analysis in CI internal combustion engine. Renewable Energy 2018:121:568-578. https://doi.org/10.1016/j.renene.2018.01.048

[35] Madiwale S., Karthikeyan A., Bhojwani V. Properties investigation and performance analysis of a diesel engine fuelled with Jatropha, Soybean, Palm and Cottonseed Biodiesel using Ethanol as an additive. Materials Today: Proceedings 2018:5(1):657-664. https://doi.org/10.1016/j.matpr.2017.11.130

[36] Cavalheiro L. F., et al. Characterization of residues and evaluation of the physico chemical properties of soybean biodiesel and Biodiesel: Diesel blends in different storage conditions. Renewable Energy 2020:151:454-462. https://doi.org/10.1016/j.renene.2019.11.039 
[37] Zhang C., et al. Assessment of biodiesel plant waste heat recovery with respect to economics and $\mathrm{CO}_{2}$ emission. Energy Procedia 2017:142:1100-1105. https://doi.org/10.1016/j.egypro.2017.12.363

[38] Muthuraman S., Sivaraj M., Rajkumar S. Performance analysis of compression ignition (CI) engine using Biodiesel. Mat Tod: Proc 2020:37(P2):1422-1426. https://doi.org/10.1016/j.matpr.2020.06.598

[39] Jagtap S. P., Pawar A. N., Lahane S. Improving the usability of biodiesel blend in low heat rejection diesel engine through combustion, performance and emission analysis. Renewable Energy 2020:155:628-644. https://doi.org/10.1016/j.renene.2020.03.115

[40] Krishania N., et al. Investigations of spirulina, waste cooking and animal fats blended biodiesel fuel on auto-ignition diesel engine performance, emission characteristics. Fuel 2020:276:118123. https://doi.org/10.1016/i.fuel.2020.118123

[41] Mirbagheri S. A., Ardebili S. M., Kiani M. K. Modeling of the engine performance and exhaust emissions characteristics of a single-cylinder diesel using nano-biochar added into ethanol-biodiesel-diesel blends. Fuel 2020:278:118238. https://doi.org/10.1016/j.fuel.2020.118238

[42] Simsek S., Uslu S. Comparative evaluation of the influence of waste vegetable oil and waste animal oil-based biodiesel on diesel engine performance and emissions. Fuel 2020:280:118613. https://doi.org/10.1016/j.fuel.2020.118613

[43] Ali M. A., et al. Biodiesel synthesized from waste cooking oil in a continuous microwave assisted reactor reduced PM and NOx emissions. Environmental Research 2020:185:109452. https://doi.org/10.1016/j.envres.2020.109452 